\title{
Early treatment of aortic stenosis will prevent poor outcomes and save thousands of lives
}

\author{
Thierry-Pierre Carrel, MD, ${ }^{\mathrm{a}}$ Walter Dembitsky, MD, ${ }^{\mathrm{b}}$ Gilles Dreyfus, MD, ${ }^{\mathrm{c}}$ Gerard Champsaur, MD, ${ }^{\mathrm{d}}$ \\ Ghislaine Deklunder, MD, PhD, ${ }^{\mathrm{e}}$ Willem Flameng, MD, PhD, ${ }^{\mathrm{f}}$ Reiner Körfer, MD, ${ }^{\mathrm{g}}$ Didier Lapeyre, MD, ${ }^{\mathrm{h}}$ \\ Bas de Mol, MD, ${ }^{\mathrm{i}}$ and Bart Meuris, $\mathrm{MD}^{\mathrm{f}}$
}

In 2005, approximately 5 million adults in the United States were diagnosed with aortic valve disease. In individuals aged 65 years and older the prevalence increased dramatically from $8 \%$ in people aged 65 to 79 years to $16 \%$ for those aged 80 to 84 years. Valve replacement most often is delayed as well as largely underused $(<10 \%)$ for these individuals. ${ }^{1}$ The development of symptoms has been the primary driver for surgical intervention. The undisputed paradigm of the past 4 decades is that clinical observation was appropriate for treating patients with aortic stenosis. The Current American College of Cardiology/American Heart Association guidelines (2008) recommend surgery for asymptomatic patients only as a class IIb indication. ${ }^{2}$

Recent clinical evidence challenges this old strategy. Since the efficacy of targeted medical therapies to slow down aortic stenosis progression was invalidated by several randomized clinical trials (unbroken progression of $\sim 6 \mathrm{~mm}$ $\mathrm{Hg}$ mean gradient per year, $0.1 \mathrm{~cm}^{2} / \mathrm{y}$ valve area reduction), the risk of watchful waiting strategy now appears greater than the risk of surgery. ${ }^{3}$ Many studies have shown that long-term results of aortic valve replacement vary considerably depending on the timing of surgery. When surgery is performed early, patients can live for 15 years and more with a high quality of life, and at a low cost. These patients can be considered cured because their life expectancy is equivalent to that of individuals of the same age in the general population. ${ }^{3}$ In contrast, when patients are treated after the onset of symptoms, life expectancy is greatly reduced regardless of age, and is much more costly.

We therefore question the value of the options offered to "high-risk" and inoperable patients because treatment at this stage can be considered palliative. A very large

From the Clinic for Cardiovascular Surgery, ${ }^{\text {a }}$ University Hospital Berne, Bern, Switzerland; Sharp Hospital, ${ }^{\mathrm{b}}$ San Diego, Calif; Cardio-Thoracic Centre, ${ }^{\mathrm{c}}$ Monaco; Champsaur Consulting LLC, ${ }^{\mathrm{d}}$ Palo Alto, Calif; Department of Cardiology, University Hospital, Lille, France; Department of Cardiac Surgery, ${ }^{f}$ University Hospital Gasthuisberg, Leuven, Belgium; Klinikum Niederrhein, ${ }^{\mathrm{g}}$ Duisburg, Germany; Lapeyre Industries, ${ }^{\text {h }}$ Geneva, Switzerland; and AMC, ${ }^{\text {i }}$ Amsterdam, The Netherlands.

Disclosures: Authors have nothing to disclose with regard to commercial support.

Received for publication April 5, 2013; accepted for publication April 9, 2013; available ahead of print May 10, 2013.

Address for reprints: Thierry-Pierre Carrel, MD, Clinic for Cardiovascular Surgery, University Hospital, Freiburgstrasse, CH-3010 Berne, Switzerland (E-mail: thierry.carrel@insel.ch).

J Thorac Cardiovasc Surg 2013;146:4-5

$0022-5223 / \$ 36.00$

Copyright $(c) 2013$ by The American Association for Thoracic Surgery

http://dx.doi.org/10.1016/j.jtcvs.2013.04.005 statistical study in the United States based on Society of Thoracic Surgeons databases recently published in the journal Circulation reported that the median survival time in more than 7000 patients with an STS risk score of $10 \%$ or greater treated by conventional surgery was only 2.6 years. In contrast, 100,000 patients between the ages of 65 and 80 years presenting with an STS risk score of less than $4 \%$ lived for more than 10 years after aortic valve replacement with a high quality of life. After age 80, even with concomitant coronary surgery, the median survival period for these patients still exceeds 7 years. ${ }^{4}$

Although patients with severe aortic stenosis may experience angina or syncope, their predominant clinical manifestations are insidious heart failure symptoms. Overt symptoms appear late in the progression of the disease. Most importantly, increasing functional, radiologic, echocardiographic, pathologic, and biological efficient screening tools now point to a clear advantage for valvular replacement performed early for a favorable long-term outcome. ${ }^{5}$ Evidence is accumulating that subclinical myocardial alterations progress rapidly, even when ventricular ejection fraction remains normal. Increasing hypertrophy provokes interstitial fibrosis, which irreversibly degrades cardiac function. More than half of asymptomatic patients present with oftenirreversible latent pulmonary hypertension, which reduces life expectancy. The aortic valve calcium score has been shown to be an independent predictor of event-free survival in subjects with only moderate aortic stenosis. Guidelines from the European Cardiology and Cardiac Surgery Societies, updated in September 2012, recommend surgery for asymptomatic patients when exercise tests are positive, which is often the case. ${ }^{6}$ The silent transition from ventricular hypertrophy to heart failure denotes the tipping point at which the left ventricle fails under increased pressure afterload. This heralds the onset of symptoms, and a poor prognosis.

The clinical benefit of prevention of irreversible myocardial damage induced by critical aortic stenosis appears sufficiently established to spare the need for randomized prospective studies to compare the mortality rate of the watchful waiting strategy with the mortality rate after preemptive valvular replacement. Such complex studies would be difficult to complete for obvious ethical reasons. In addition, randomization may pose methodologic problems because a significant number of observed asymptomatic patients are likely to develop symptoms throughout the 
study and cross-over to the therapeutic arm. Achieving sufficient statistical significance would take many years.

Because patients at low risk can be considered cured by surgery and because it is established that untreated aortic stenosis ineluctably induces irreversible myocardial damage, it is counterintuitive that long-term outcomes of the wait-and-see strategy will be better than those of the pre-emptive option.

Progress in diagnostics should finally end this old dilemma and reverse the growing epidemic of end-stage patients who become candidates for palliative procedures.

When pathology puts the vital prognosis at stake, prevention is always the best therapy. This rule is well established for cancer and most life-threatening diseases. Given the high frequency, severe aortic stenosis (the next cardiac epidemic) should be no exception. Therefore, greater attention should be given to the early detection of silent aortic stenosis and to the timing of surgery using proven methods and replacement valves. This action greatly would reduce the number of patients defined as nonoperable or high risk.

After 10 years and more than an estimated 50,000 implants worldwide, transcatheter valve therapy still remains experimental. Procedure complexity, vascular complications, site calcification, paravalvular leaks, conduction disturbances, and stroke are frequent barriers to safe and efficient implementation. Because long-term risks and benefits of this procedure remain largely unknown, there is no reason to wait until this technology eventually is improved to reconsider the prevailing watchful waiting paradigm when well-established surgical procedures can have an immediate and profound impact on patient longevity and quality of life. The large retrospective review mentioned earlier ${ }^{4}$ strongly suggests that systematic detection and early treatment would save thousands of lives and allow for a substantial cost savings.

The right timing for a surgical intervention is always weighed against the risks of the procedure and the implanted device. Our current commercial valves are still based on designs, materials, and tissue-preservation methods from the 1970 s and 1980 s. "In contrast to the pioneering years, courage and incentive towards a new developmental quantum leap have been mostly absent from commercial product strategies." Although transcatheter valve procedures offer a palliative option for the elderly, the needs of younger patients for an anticoagulantindependent and durable-for-life heart valve substitute still have not been met. If better valve substitutes were available, this would shift the balance further toward earlier intervention and improved outcomes.

The authors wish to thank Rolland Siegel and Lawrence N. Scotten, DiplT, for their generous assistance in the preparation of this manuscript.

\section{References}

1. Bach DS, Jasmina I, Radeva JI, Birnbaum HG, Fournier A-A, Tuttle EG. Prevalence, referral patterns, testing, and surgery in aortic valve disease: leaving women and elderly patients behind? J Heart Valve Dis. 2007;16:362-9.

2. Bonow RO, Carabello BA, Chatterjee K, de Leon AC Jr, Faxon DP, Freed MD, et al. 2008 focused update incorporated into the ACC/AHA 2006 guidelines for the management of patients with valvular heart disease: a report of the American College of Cardiology/American Heart Association Task Force on Practice Guidelines (Writing Committee to revise the 1998 guidelines for the management of patients with valvular heart disease). Endorsed by the Society of Cardiovascular Anesthesiologists, Society for Cardiovascular Angiography and Interventions, and Society of Thoracic Surgeons. J Am Coll Cardiol. 2008;52: e1-142.

3. Vasques F, Messori A, Lucenteforte E, Biancari F. Immediate and late outcome of patients aged 80 years and older undergoing isolated aortic valve replacement: a systematic review and meta-analysis of 48 studies. Am Heart J. 2012;163: 477-85.

4. Brennan JM, Edwards FH, Zhao Y, O’Brien SM, Douglas PS, Peterson ED. Longterm survival following aortic valve replacement among high-risk elderly patients in the United States: insights from the STS adult cardiac surgery database. Circulation. 2012;126:1621-9.

5. Bonow RO. Exercise hemodynamics and risk assessment in asymptomatic aortic stenosis. Circulation. 2012;126:803-5.

6. Vahanian A, Alfieri O, Andreotti F, Antunes MJ, Barón-Esquivias G Baumgartner $\mathrm{H}$, et al. Guidelines on the management of valvular heart disease (version 2012): the Joint Task Force on the Management of Valvular Heart Disease of the European Society of Cardiology (ESC) and the European Association for Cardio-Thoracic Surgery (EACTS). Eur J Cardiothorac Surg. 2012;42:S1-44. 